\title{
PROCEDURES IN THE BIOCHEMICAL ESTIMATION OF AGE OF VERTEBRATES
}

\author{
Joseph G. OTERo and Richard W. DAPSON
}

Department of Biology, University of Michigan-Flint, Flint, Michigan 48503, U.S. A.

Population studies frequently require accurate age-estimating techniques. Eye lenses are often utilized because of their anatomic and physiologic isolation from blood vessels, accessibility without contamination by other tissues, and apparent continuous growth throughout life. Procedures dealing with lens weight are often superior to other techniques (FRIEND, 1967), but do not take advantage of certain precise alterations in lens biochemistry.

Dische (1956) has described age-associated changes in rat lenses. New watersoluble protein is first added to the growing lenses. With age, this protein becomes insoluble, presumably by conversion of cyteine to cystine.

DAPSON et al. (1968) described a method for assaying soluble and insoluble lens fractions in white mice, and suggested using it for estimating age. Later work on laboratory-reared old-field mice, Peromyscus polionotus, (DAPSON and IRLAND, in press) demonstrated the value of this suggestion for insoluble fractions. Ninety-five percent confidence limits about an average estimaton of 100 days were 96-107 days; for 300 days, 293-319 days; and for 700 days, 680-751 days. The technique thus provides unprecedented accuracy and permits refined demographic study of wild populations. Soluble protein content was an unreliable indicator of age.

The method consists of two basic procedures: obtaining the appropriate lens fraction, and quantitatively analyzing its protein composition. To obtain the insoluble fraction, the lens is removed from its eyeball and homogenized. Insoluble material is separated by centrifugation from the soluble component, dissolved, and may be stored frozen if desired.

Quantification of insoluble material is achieved by determining the amount of one of its component amino acids, tyrosine. The amount of tyrosine is used as an index of the amount of protein, and is closely correlated with age (DAPSON and IRLAND in press.). Reagents are added to the fractions and a colored complex with tyrosine is produced. The intensity of color is measured with a colorimeter and compared with known concentrations of tyrosine. Values from wild specimens are then compared with known-age data.

A review of the entire procedure is warranted at this time because of three reasons: many improvements have been made since the original description in 1968; the method has potential as an important new tool for population ecologists; and many ecologists are not familar with certain microchemical or biochemical techniques. 


\section{Materials}

\section{Equipment}

Distilled or deionized distilled water should be employed throughout the procedure. Prior to use, all glassware should be washed with a laboratory grade detergent, rinsed in hot water, soaked briefly in $5 \% \mathrm{HCl}$, and rinsed with three changes of distilled water. Cleanliness is stressed because the Folin-Ciocalteau reagent used here may react with carbohydrates or other contaminants left on unclean glass (BoNITATI et al., 1969).

Accurate delivery of all reagents is imperative. For volumes of $0.5 \mathrm{ml}$ or less Mohr measuring pipettes are preferred. Serological pipettes (calibrated to tip) are allowable but less accurate where total volumes must be blown out. Some reagents are noxious, however, and continuous pipetting by mouth can result in severe mouth and throat irritation even without an overt pipetting accident. Different-sized burettes (automatic filling types if possible) are safe, accurate and convenient for routinely delivering the same volume of reagent.

Glass tissue grinders are used to homogenize lenses, and their size will vary with the size of the lenses under study. For mice and small frogs, a 1-3 ml Micro Tissue Grinder (Will Corp.) is ideal.

Miscellaneous small equipment includes watchmaker's forceps, razor blades, a large supply of Pasteur pipettes, and volumetric flasks of various sizes. The most convenient centrifuge tubes are alkali-resistant plastic that withstand freezing temperatures and high speed centrifugation. Their low cost permits centrifugation and immediate storage of large numbers of samples. Their size will depend on the lenses. For small vertebrates, we use $10 \mathrm{ml}$ tubes. Several hundred test tubes $(10-30 \mathrm{ml})$ are needed, and should be made of alkali- and low temperature-resistant plastic or glass.

The centrifuge must be run routinely at $12,000 \mathrm{x}$, and should have a maximum rating above $20,000 \mathrm{xg}$. A refrigerated unit is preferable, and should be operated at $10^{\circ} \mathrm{C}$ to avoid heating the material. Either a single-beam or double-beam spectrophotometer may be used for colorimetric analyses. Directions for each are given below. Small cuvettes must be used with the volumes indicated. We have used a Bausch and Lomb Spectronic 20 with Roto-Cell Assembly and infrared-sensitive phototube and filter for our single-beam instrument, and a Beckman DB-G double-beam spectrophotometer. Similar instruments should serve satisfactorily.

A four or five place analytical balance is needed to weigh the tyrosine. Less sensitive instruments are satisfactory for other dry reagents. A thermostatically controlled water bath is needed for incubation of solutions.

\section{Reagents}

Tyrosine for standards is stored in a vacuum desiccator or any airtight container with desiccant away from direct light. A stock solution containing 7-11 $\mu \mathrm{g}$ tyrosine/100 
$\mathrm{ml}$ water is prepared weekly; fresh standard solutions are prepared therefrom daily according to Table 1. Each dilution should be duplicated at least once to increase the accuracy of the standard curve.

An "alkaline solution" is made with a 1: 1: 100 mixture of $4 \% \mathrm{NaK}$ tartrate, $2 \%$ $\mathrm{CuSO}_{4}$ and $4 \% \mathrm{Na}_{2} \mathrm{CO}_{3}$. The latter is prepared by boiling water $15 \mathrm{~min}$., adding $\mathrm{Na}_{2} \mathrm{CO}_{3}$, cooling and filtering (LowRY et al., 1951). Commercially prepared color (Folin-Ciocalteau) reagent is diluted with an equal volume of water before use. A copperprotein complex, formed in alkaline solution, reduces the Folin-Ciocalteau reagent and changes its color from yellow to blue.

\section{Methods}

\section{Preparation of lens material}

Fresh material must be used because preservatives may precipitate protein. Insoluble lens protein may be recovered as follows: Sacrifice the animal. Dissect out intact lense by applying pressure to the bact of the eyeball and gently cutting the cornea with a sharp razor blade. Carefully enlarge the incision with watchmaker's forceps. The lens will be extruded intact. Too much pressure on eyeball or razor blade will rupture the lens, rendering it useless for analysis. Adhering vitreous and ciliary material can be removed by rolling the lens along bibulous (blotting) paper. However, excessive rolling will unencapsulate tiny lenses.

Homogenize the lens in a few drops of water and transfer the entire homogenate to a centrifuge tube with a clean Pasteur pipette. Recover protein adhering to the homogenizer and pestle by rinsing several times with distilled water and adding solution to the centrifuge tube. Sediment insoluble protein by centrifugation at $12,000 \mathrm{xg}$ for 20 minutes, preferably under refrigeration. Plastic tubes should be about threequarters full to avoid compressing their walls. Pour off and discard the supernatant soluble fraction.

If storage of the insoluble fraction is desired, plastic centrifuge tubes can be deepfrozen. Alternately, the insoluble pellet may be dissolved in a known volume of 0.5 $M \mathrm{NaOH}$ and deep-frozen in Pyrex or plastic test tubes. The volume of $\mathrm{NaOH}$ used is critical and depends on the concentration of protein. Further details on this will be given below.

Certain lenses are difficult to centrifuge because of their small size or insufficient content of insoluble material. Under these conditions, insoluble material can be recovered by filtration. Each homogenate is pipetted into a vertically-held $10 \mathrm{ml}$ hypodermic syringe, fitted with a Swinney adapter containing a 0.5 inch sterilizing-grade Seitz asbestos filter (unit available from Scientific Products). Two or more filters may be sequentially required for each lens. Remove adapter from the syringe barrel, withdraw the plunger and replace adapter. Rinse tissue from wall of barrel, replace plunger and filter this rinse water. Repeat several times. Discard filtrate, remove filter and rinse syringe and adapter before re-use. 
Filters may be stored in a deep-freezer. Prior to analysis, dissolve insoluble protein embedded in the filter with a known volume of $0.5 \mathrm{M} \mathrm{NaOH}$.

Determination of initial dilution factor

Insoluble protein should be dissolved in a volume of $0.5 \mathrm{M} \mathrm{NaOH}$ that will yield colorimetric readings within the range of sensitivity of the instrument. With most species, unfortunately, the same initial volume for all lenses will not produce these result without further manipulation. With single-beam colorimeters, older lens solutions must be further diluted. With double-beam instruments, the machine is manipulated instead. Regardless of the type of colorimeter used, an initial solution must be made that will not be too dilute. Concentrated solutions reading beyond the range of sensitivity can be further diluted; but overly dilute solutions cannot be corrected easily.

Having the smallest amount of insoluble protein, the youngest lens can be used to determine the initial volume of solvent for all other lenses of the species. Dissolve the youngest insoluble pellet or Seitz filter precipitate in $1.0 \mathrm{ml} 0.5 \mathrm{M} \mathrm{NaOH}$. Dilute aliquots of this solution 2 to 100 fold with $0.5 \mathrm{M} \mathrm{NaOH}$. Perform Lowry tests (described below) on these solutions, and select the dilution that reads closest to $50 \% \mathrm{~T}$. All other lenses of this species can be hydrolyzed initially at this concentration. For example, if a 1:10 dilution (1 part lens solution and 9 parts $\mathrm{NaOH}$ ) gives a reading of $50 \% \mathrm{~T}$, all other samples could be dissolved initially in $10 \mathrm{ml} 0.5 \mathrm{M} \mathrm{NaOH}$ instead of $1 \mathrm{ml}$.

\section{Secondary dilutions with single-beam colorimeters}

If a standard single-beam colorimeter is used, each fraction will require a range of dilutions to insure that one of them will read near $50 \% \mathrm{~T}$. Ideally, readings should lie between $40 \%$ and $60 \% \mathrm{~T}$, and none should be outside the $30-70 \% \mathrm{~T}$ range. This roughly corresponds to a concentration of $35-65 \mu \mathrm{g} / \mathrm{ml}$.

With small animals, the difference between youngest and oldest is usually 4 -fold and rarely greater than 10 -fold. Dissolve the oldest lens pellet or filter precipitate in the initial volume determined from the preceding section. Dilute aliquots of this solution 1:2, $1: 4$ and $1: 10$ with $0.5 \mathrm{M} \mathrm{NaOH}$ ( 1 part lens solution with 1 part $\mathrm{NaOH}$ makes a 1: 2 dilution, etc.). Perform Lowry tests on these diluted solutions, and select the one giving a reading closest to $50 \% \mathrm{~T}$. All other lenses of this species will contain an amount of insoluble protein intermediate between youngest and oldest values, and must secondarily be diluted accordingly. With unknown-age material, several different secondary dilutions that span this range must be made for each lens.

Great care must be taken in making secondary dilutions to prevent large analytical errors. Duplicate dilutions should be made, and their readings averaged to minimize such error. These precautions are time consuming necessities with single-beam instruments; secondary dilutions are eliminated altogether with double-beam spectrophotometers. 


\section{Lens analysis with single-beam colorimeters}

In simplest terms, our colorimetric analysis of lens proteins is based on comparing color "intensity," absorbance, or \% transmittance of a hydrolyzed, unknown sample against standards containing known amounts of tyrosine. The standard curve is expressed in $\mu$ g tyrosine $/ \mathrm{ml}$; results of lens analyses are given in $\mu \mathrm{g}$ tyrosine per insoluble fraction. The analytical procedure is the Lowry test (LowRY, et al., 1951).

To each $0.5 \mathrm{ml}$ solution of tyrosine or lens protein, add $5.0 \mathrm{ml}$ alkaline solution, mix well and incubate for $15 \mathrm{~min}$. at $40^{\circ} \mathrm{C}$ in a water bath. Cool and add $0.5 \mathrm{ml}$ diluted Folin reagent. After $30 \mathrm{~min}$., color intensity is fully developed and can be measured at $700 \mathrm{~nm}$. Color is stable for at least two hours. Reagent blanks containing Lowry reagents and $0.5 \mathrm{ml}$ water instead of tyrosine or lens protein are used to zero the machine.

All readings should be made in $\%$ transmittance, because accurate interpolations cannot be made visually on the absorbance scale. Transmittance is converted to absorbance by formula or table (as in DunN and ARdiTt1, 1968). The regression of absorbance on tyrosine concentration of standard solutions is determined by the method of least squares (Simpson et al., 1960; STEel and Torrie, 1960), and this equation is then used to find tyrosine concentration from absorbance values of lens solutions. Standard curves should not be estimated by plotting data on graph paper. Accurate apprisal of this relationship is essential, and can only be attained through mathematical methods.

Standard solutions must be prepared and read daily, and their regres sion equation used to determine tyrosine concentration of all lenses analyzed that day. This routine is necessary because of daily fluctuations in line voltage and long-term changes in the characteristics of electronic tubes.

When secondary dilutions of unknown material are tested, the concentration of lens tyrosine derived from the regression equation must be multiplied by the total dilution factor to determine the amount of tyrosine in the insoluble lens fraction. For example, assume that a 1:4 dilution of an initial $2 \mathrm{ml}$ solution gives a reading of $50 \% \mathrm{~T}$. Further assume that this corresponds to $40 \mu \mathrm{g}$ tyrosine $/ \mathrm{ml}$ on the standard curve for that day. The total dilution factor is $8(4 \times 2)$ and the lens contained 320 $\mu g$ tyosine $(8 \times 40)$. If dilutions have been duplicated, their values are combined with those of the other lens from the same animal, and a mean tyrosine content is determined for each individual.

\section{Lens analysis with double-beam spectrophotometers}

With a double-beam spectrophotometer, the range of concentrations providing readings between 40 and $60 \% \mathrm{~T}$ is approximately $35-165 \mu \mathrm{g} / \mathrm{ml}$, without secondary dilutions. This is four times the range of single-beam colorimeters, and has been more than adequate for all material thus far studied. The possiblity for making errors with secondary dilutions is elminated, and time involved with the analysis is reduced substantially. Furthermore, all readings fall nearly at $50 \% \mathrm{~T}$, and thus are within the same 
Table 1. Preparation of diluted standard tyrosine solutions.

Stock solution should contain $70-110 \mu \mathrm{g}$ tyrosine $/ \mathrm{ml}$.

\begin{tabular}{cccc}
$\begin{array}{c}\text { Tube } \\
\text { number }\end{array}$ & Stock $(\mathrm{ml})$ & Water $(\mathrm{ml})$ & $\begin{array}{c}\text { Tyrosine } \\
(\mu \mathrm{g} / \mathrm{ml})\end{array}$ \\
\hline 1 & 0.50 & 0.00 & $70-110$ \\
2 & 0.45 & 0.05 & $63-99$ \\
3 & 0.40 & 0.10 & $56-88$ \\
4 & 0.35 & 0.15 & $49-77$ \\
5 & 0.30 & 0.20 & $42-66$ \\
6 & 0.25 & 0.25 & $35-55$ \\
7 & 0.20 & 0.30 & $28-44$ \\
8 & 0.00 & 0.50 & 0 \\
\hline
\end{tabular}

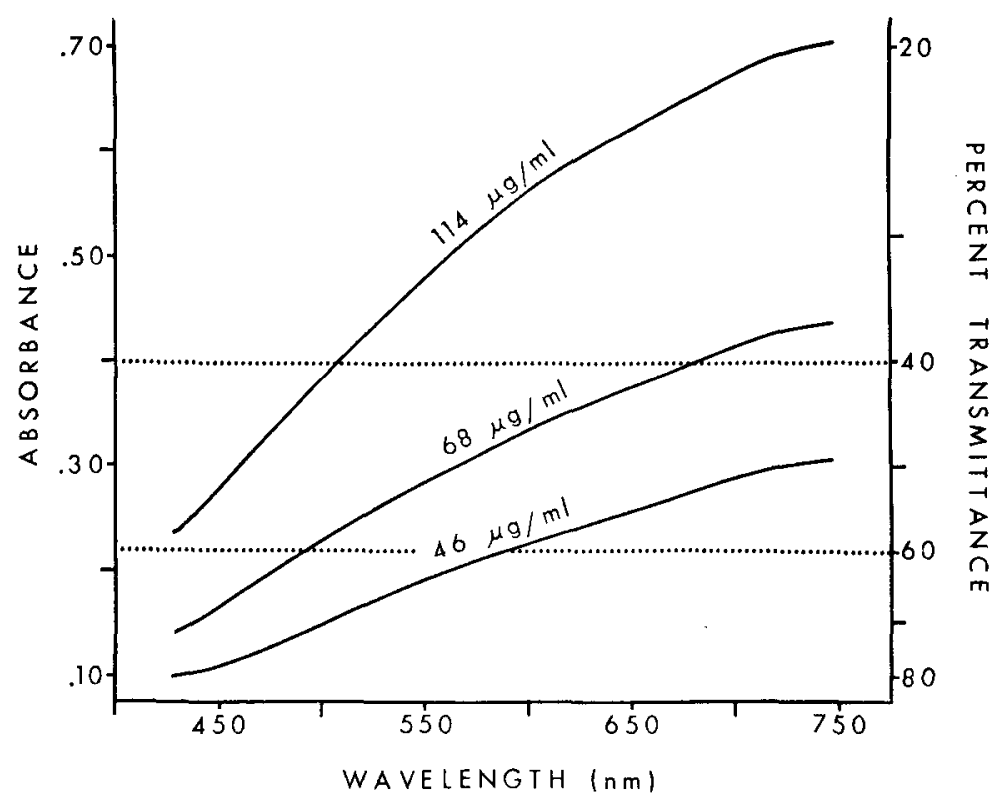

Fig. 1. Spectral characteristics of three concentrations of tyrosine treated with the Lowry test. Dotted lines delimit the range of maximum sensitivity of the colorimeter. For greatest accuracy, only those values between dotted lines should be used.

range of sensitivity of the instrument.

Standard tyrosine solutions are made according to Table 1 , and all are read at $450,500,550,600,650$, and $700 \mathrm{~nm}$. Fig. 1 shows spectral characteristics of three solutions of tyrosine at arbitrary concentrations of 46,68 , and $114 \mu \mathrm{g} / \mathrm{ml}$. At $700 \mathrm{~nm}$, only the most dilute of these solutions falls within the acceptable range of transmittance $(40-60 \%)$. With a single-beam colorimeter, the other two solutions 
would require secondary dilution. However, between 650 and $500 \mathrm{~nm}$, the second solution lies within the acceptable range. The most concentrated solution can be read at 450 or $500 \mathrm{~nm}$.

A family of standard curves can be generated from this data, each curve representing the relationship between absorbance and concentration (Fig 2). The regression equation for each curve is determined by the method of least squares, using only those values between 40 and $60 \% \mathrm{~T}$ for each wavelength. To obtain a reading within the acceptable range for a lens fraction, choose the wavelength which most closely provides a reading of $50 \%$ transmittance. Concentration and appropriate wavelength are inversely related. Thus, solutions with transmittance values above 60 $\%$ at a given wavelength should be measured at a longer wavelength, and vice versa. To translate absorbance into concentration, solve the regression equation for the standard curve corresponding to the wavelength used.

For example, assume that an unknown lens fraction has a transmittance of $29 \%$ at $700 \mathrm{~nm}$. With a single-beam instrument, secondary dilutions would be necessary to bring the reading into the acceptable range. With a doule-beam instrument, the original sample is simply read at $500 \mathrm{~nm}$, where its transmittance is $49 \%$. This corresponds to a concentration of $90 \mu \mathrm{g} / \mathrm{ml}$ on the $500 \mathrm{~nm}$ standard curve in Fig. 2.

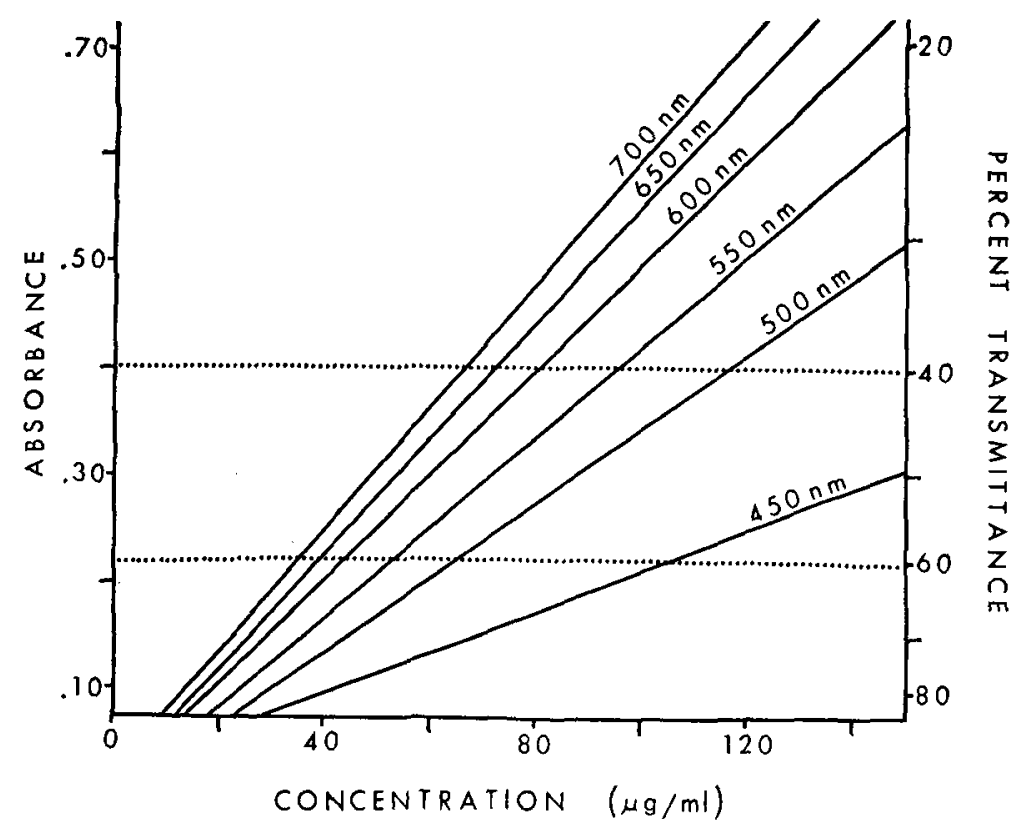

Fig. 2. Standard curves showing the relationship between tyrosine concentrations and optical properties at six different wave lengths. For a given concentration, a wave length that provides a reading near $50 \% 6$ transmittance should be used. 


\section{Comparison of known and unknown animals}

After lenses of known-age material have been analyzed, the relationship between age and insoluble tyrosine content can be determined mathematically. On species studied thus far, this relationship was curvilinear and was straightened by logarithmic transformations to permit rectilinear regression analysis. Details of this procedure. including formulae for confidence limits, are given by DAPSON and IRLAND (in press). This regression equation is used to estimate ages of wild animals whose lenses have been assayed.

\section{SUMMARY}

The most accurate method known to date for estimating age of wild vertebrates involves biochemical assay of eye lens proteins. Laboratory procedures that may be unfamiliar to many ecologists are described in detail. The method is based on precise changes in the amount of insoluble lens protein, and consists of two procedures: obtaining the appropriate lens fraction, and quantitatively analyzing its protein composition. Lenses are homogenized, and the insoluble fraction isolated by centrifugation. Protein content is measured colorimetrically by using the Lowry test. Instructions are given for single and double-beam spectrophotometers.

\section{Literature Cited}

Bonitati, J., W. B. Elliot and P. G. Miles (1969) Interference by carbohydrate and other substances in the estimation of protein with the Folin-Ciocalteau reagent. Anal. Biochem. 31: 399404.

Dapson, R.W. and J.M. JrLand (In press) An accurate method of determining age in small mammals. Jour. Mamm. 53.

Dapson, R.W., J.G. Otero, and W.S. Holloway, Jr. (1968) Biochemical changes with age in the lenses of white mice. Nature 218: 573.

Dische, Z., E. Borenfreund, and G. Zelmenis (1956) Changes in lens proteins of rats during aging. Arch. Ophthal. 55: 471-483.

Dunn, A. and J. Arditti (1968) Experimental physiology. Holt, Rinehart, and Winston, New York.

FrIENd, M. (1967) A review of research concerning eye-lens weight as a criterion of age in animals. N.Y. Fish and Game Jour. 14: 152-165.

Lowry, O. H., N. J. Rosebrovgh, A. L.FAn, and R. J. RandalL (1951) Protein measurement with the Folin phenol reagent. Jour. Biol. Chem. 193: 265.

Simpson, G. G., A. Roe, and R. C. Lewonrin (1960) Quantitative zoology. N. Y., Harcourt, Brace, and World. $440 \mathrm{p}$.

Steel, R.G.D. and J.H. Torrie (1960) Principles and procedures of statistics. N. Y., McGrawHill. $481 \mathrm{p}$. 


\section{眼球の生化学的組成の分析による}

脊椎動物の年分推定法について

J. G. Otero - R. W. Dapson

脊椎動物の年令を間接的に推定するための諸方法の中で最も正碓なものの1 つに眼球の蛋白賀の分析によ る方法があげられる。この場合年令推定の基礎を眼球の不溶性蛋白質の量にわいており，眼球の一部を摘出 し，それに含まれる蛋白質を定量するという操作が必要である。この方法を実際に適用する上での具体的な 手順や問題点を詳細にのべた。 